\title{
Hacia una construcción del sujeto en Michel Foucault
}

Towards a construction of the Self in Michel Foucault

Rosalía Gil Fernández*

\begin{abstract}
Resumen
Este artículo hace un recorrido por las obras de Michel Foucault que incursionan en la construcción de la subjetividad y su relación con el cuerpo humano. En Foucault esto se realiza a través de las 'Tecnologías de Si," que incluyen la inquietud y el cuidado de Sí, durante los períodos históricos que inician en tiempos greco-romanos y terminan en los albores de la modernidad.
\end{abstract}

Palabras clave: Foucault, tecnologías de si, subjetividad, genealogía, cuerpo.

\begin{abstract}
This article runs through the works of Michel Foucault that deal with the construction of subjectivity and its relationship with the human body. In Foucault, this is done through the "Technologies of Self," that include self questioning and care oneself, during the historical periods that start in greco-roman times and end with the beginning of modernity.
\end{abstract}

Key Words: Foucault, technologies of the self, subjectivity, genealogy, body.

* Universidad de Costa Rica. Maestría Académica en Psicología. Correo electrónico: rosaliagil1@ hotmail.com

Recibido: 9/10/17 Aceptado: 20/2/18. 


\section{Introducción}

A lo largo de su obra puede observarse el interés de Foucault en los procesos que constituyen la construcción de la subjetividad. Inicialmente lo presenta desde el análisis de una arqueología, que es diferente al análisis de la historia, (Abreo, 2011) luego lo hace dentro de una genealogía, que se aproxima a la historia desde la discontinuidad y el enfrentamiento de fuerzas de poder, para finalmente realizarlo desde la Hermenéutica del Sujeto, donde la propuesta gira en torno a las Tecnologías de Si. Casi toda la producción discursiva y textual de Foucault se dirige a la búsqueda de la forma en que el individuo se va constituyendo como sujeto, a partir de una secuencia genealógica que eventualmente apunta hacia la reconstrucción de la historia de las subjetividades modernas.

Para llegar a integrar una hermenéutica del Sujeto que logre abordar en forma transversal la contemporaneidad a través de la historia, su escritura es la escritura de Si, su discurso es el discurso de Sí, en una constante búsqueda de la subjetivación de la verdad en el marco de las Tecnologías de Sí. La Hermenéutica del sujeto, publicado en 1982, presenta una elaborada propuesta sobre la construcción de la subjetividad donde el recorrido inicia con los preceptos de la episteme antigua en El Alcibíades de Platón, continúa en los Siglos I y II de la Época Helénica y finaliza en los albores del Cristianismo. Esta integración individual del Yo se logra dentro de un contínuum de retroalimentación interpersonal:

El hombre es central en su propia subjetividad y en la de los demás. Por todas partes, el hombre se preocupa de sí mismo, pero a la inversa, este mismo hombre transmite las semejanzas que él recibe del mundo. Es el gran foco de las proporciones - el centro en el que vienen a apoyarse las relaciones y de donde son reflejadas de nuevo. (Foucault, 1966, p. 32.)

El ser humano y su circunstancia son el punto focal de los temas que Foucault aborda sobre la identidad, la existencia, el cuerpo y la verdad. Un ser "sapiente" que se cuestiona sin cesar sobre su existencia, su propósito, su finitud y su salvación. 


\section{Genealogía del sujeto - Tecnologías de Sí}

La genealogía, en tanto una forma no tradicional de análisis desde la historia, tiene la capacidad de mover, discutir y disociar determinadas circunstancias existenciales. Foucault (1975) al intentar construir una historia de la subjetividad, o una genealogía del sujeto, privilegia prácticas sociales relacionadas al ejercicio del poder y a las estrategias de disciplina y normalización direccionadas al cuerpo físico, por el cuerpo político, social e institucional en un período de tiempo determinado. Poder y saber se implican directamente el uno con el otro. En Foucault, el poder y el saber se ejercen en forma correlacionada porque para él "no existe relación de poder que no constituya al mismo tiempo unas relaciones de saber." (Foucault, 1975, p. 34.) En este sentido, el poder produce un saber y existen ejercicios de poder en el funcionamiento de los saberes. La subjetividad se produce en el interior de estos campos de saber.

Dentro del análisis genealógico, el autor analiza las relaciones de poder, campos de saber, cuerpos, sociedades, y procesos de normalización dentro de tres posibilidades o dominios: Ontología histórica de nosotros mismos, en relación con la verdad, al constituirnos como sujetos de conocimiento; ontología de nosotros mismos en relación con el campo de poder, al constituirnos como sujetos que actúan sobre otros y ontología histórica del ser humano en relación con la ética, al constituirse a sí mismo como agente moral. La genealogía es también un análisis de la emergencia o la forma en que entran en escena las fuerzas violentas: es la historia de las discontinuidades, que no unifica, sino dispersa, multiplica y fragmenta lo que se creía unido. La historia genealógicamente dirigida "no tiene como finalidad reconstruir las raíces de nuestra identidad, sino dispararlas; no busca reconstruir el centro único del que provenimos, esa primera patria donde los metafísicos nos prometen que volveremos, intenta hacer aparecer todas las discontinuidades que nos atraviesan." (Foucault, 1971, p.27.) Por lo tanto, no intenta restablecer grandes continuidades o buscar una significación oculta en el origen.

Mi objetivo, desde hace más de veinticinco años, ha sido el trazar una historia de las diferentes maneras en que, en nuestra cultura, los hombres han desarrollado un saber acerca de sí mismos: una economía, biología, psiquiatría, medicina y penología. El punto crucial no consiste en aceptar este saber cómo un valor dado, sino en analizar estas llamadas ciencias como "juegos de verdad" específicos, relacionados con técnicas específicas que los hombres utilizan para entenderse a sí mismos. Existen cuatro tipos de Tecnologías de Sí, a saber: tecnologías de producción, que nos permiten producir, transformar, o manipular cosas. Tecnologías de sistemas de signos, que nos permiten 
utilizar signos, sentidos, símbolos o significaciones. Tecnologías de poder, que determinan la conducta de los individuos, los someten a cierto tipo de fines o dominación y consisten en una objetivación del sujeto. Tecnologías del yo, que permiten a los individuos efectuar, por cuenta propia o con ayuda de otros, cierto número de operaciones sobre su cuerpo y su alma, pensamientos, conducta, o cualquier forma de ser, obteniendo así una transformación de sí mismos con el fin de alcanzar cierto estado de felicidad, pureza, sabiduría o inmortalidad. Estos tipos de tecnología casi nunca funcionan de forma separada, aunque cada una de ellas esté asociada a algún tipo particular de dominación. Cada una implica ciertas formas de aprendizaje y modificación de los individuos, en la adquisición de ciertas habilidades y actitudes... Cada vez estoy más interesado en la interacción entre uno mismo y los demás, así como en las teorías de dominación individual, la historia del modo en que un individuo actúa sobre sí mismo, es decir, en la tecnología del yo. (Foucault, 1990, p. 45.)

El desarrollo de la subjetividad en Foucault es un saber minucioso, erudito y paciente donde ésta no podría entenderse si no es dentro de las relaciones que emanan de los campos del saber y de las luchas de poder y no podría entenderse si no es dentro del punto de ruptura específico que produce nuevas tensiones entre ambos. Para analizar las Tecnologías de $\mathrm{Si}$, seguiremos la línea de pensamiento foucoltiano que considera que el conocimiento de Sí Mismo es un elemento constitutivo de la Inquietud de Sí (Foucault, 1982, p. 77.) Debido a sus implicaciones en la construcción de la subjetividad, esta inquietud, o cuestionamiento, que conlleva el cuido de Sí, es muy importante a lo largo de toda la civilización griega, helenística y romana.

\section{En el momento Greco-Romano}

Durante los años 80, Foucault se aleja de la modernidad para remontarse siglos atrás. Incursiona en el análisis de la subjetividad en El Acibíades de Platón y se va a preocupar más sobre la construcción del sujeto como un proyecto de soberanía individual. Hablará sobre el cuido de sí, la inquietud de sí, la cultura de sí, y el gobierno de sí, dentro de una serie de prácticas o tecnologías ascéticas, corporales y sexuales, dirigidas la búsqueda personalizada de la verdad en el sí mismo.

Foucault enmarca la subjetividad, dentro de un análisis que es tanto genealógico como arqueológico, donde la arqueología viene a ser el análisis de lo que existe, de lo que es, dentro de una práctica discursiva con el hombre como principal objeto de estudio. En la época de Alcibíades esta práctica tiene que ver con un viaje dirigido a que el sujeto, con la mediación de un maestro que le siembra una inquietud, aprenda el gobierno de sí mismo y se convierta en lo que es, en su verdad. En la cultura griega la "epimeleiaheautou" o la Inquietud de Sí, va siempre ligada a la subjetividad o 
"gnothiseauton," que significa Conócete a Ti Mismo. Para Foucault esta es la fórmula fundadora de las relaciones entre sujeto y verdad que emerge en Sócrates, asignado por los Dioses del Olimpo como "quien despierta," como el mediador que incita a los jóvenes de su tiempo, a conocerse, a despertar y a cuidar de sí mismos para emprender el justo camino de la vida. Esta inquietud de Sí es: "una manera de estar en el mundo, una mirada atenta de afuera hacia adentro, un conjunto de acciones transformadoras, un corpus que define la subjetividad." (Foucault, 1982, p. 17-19.)

Para el autor la Inquietud o cuido de sí es un proceso que se integra a partir de tres momentos: socrático-platónico, helenístico-romano o Siglos I y II y Siglos IV y V. "Hay que ocuparse de sí mismo" es un privilegio basado en la tradición y una sentencia ancestral y plurisecular de la cultura lacedemonia. Este privilegio y la búsqueda de la verdad tal y como se propone en el diálogo platónico-socrático, transversa todo el discurso.

La Apología Socrática donde Sócrates se presenta a sí mismo ante el juez como maestro de la "epimeleiaheautou," es uno de los muchos testimonios sobre su importancia como técnica de vida, un saber muy específico, ligado al auto-conocimiento y a la filosofía. Es un tipo de pensamiento que se interroga sobre aquello que le permite al sujeto trabajar para ingresar a la verdad, porque nunca se da en pleno derecho. Al estilo délfico, aquí no puede haber acceso a la verdad, sin una disponibilidad e intencionalidad conducentes a la modificación personal en el arduo camino hacia sí mismo. "El principio délfico no era un principio abstracto referido a la vida, era un consejo práctico, una regla que debía de ser observada para consultar al oráculo. Conócete a ti mismo quería decir "No supongas que eres un Dios". (Foucault, 1990, p. 46.)

Platón retoma en El Alcibíades la Inquietud de Sí dentro de una tradición griega y una presencia espartana, donde Sócrates incita al joven con intensas preguntas, que iluminan su ignorancia y profundizan hasta llegar a la deseada inquietud. Enfatiza el auto-conocimiento como una herramienta ligada al crecimiento y al cuido de sí, donde se enfrentan las obligaciones futuras y se procesan las limitaciones, deseos, ambiciones y temores que surgen antes de la edad adulta. Con Alcibíades, surge la primera emergencia teórica de la "epimeleiaheautou." Sin embargo, para Foucault, las bases ya existían desde mucho antes de Sócrates, desde mucho antes que Platón:

Que la verdad no pueda alcanzarse sin cierto conjunto de prácticas exhaustivamente especificadas que transforman el modo de ser del sujeto, que lo modifican tal como está dado, que lo califican al transfigurarlo, es un tema prefilosófico que había dado lugar a muchos procedimientos más o menos ritualizados. (Foucault, 1982, p.59.) 
El texto apunta a tres temas fundamentales en relación con la Inquietud de Sí: la política o el gobierno de la ciudad, las deficiencias pedagógicas y, sobre todo, a la importancia del auto-conocimiento. Sócrates, se dirige por primera vez a Alcibíades, a quien siempre ha admirado desde lejos, para ayudarle a conocerse y por ende a manejar estos temas tan entrelazados con su capacidad para gobernar. Sócrates está menos joven, ya no lo buscan y asechan sus admiradores como lo hacían anteriormente.

Alcibíades no está listo. Desea gobernar la ciudad, sin la pedagogía, el conocimiento o el cuidado de sí mismo necesarios. Sócrates reconoce esto y se le acerca con la intención de iniciar los cuestionamientos que lo conducirán a la "tekhne," que necesita para gobernar. La relación da inicio ante el asombro sobre sí mismo que sus interrogantes producen en el joven: "Ni yo mismo se lo que digo. En verdad, es muy posible que haya vivido desde hace mucho en un estado de ignorancia vergonzosa, sin advertirlo siquiera" (Foucault, 1982, p.50.). Sócrates lo consuela diciéndole que aún no tiene cincuenta años, cuando ya sería muy difícil iniciar el proceso de cuidarse a sí mismo. Aparece así, ese cuido como un privilegio dentro del ejercicio del poder y del saber, que se adquiere cuando se es joven. No se puede gobernar a los demás sin antes haberse ocupado de sí mismo como objeto de conocimiento y de preocupación. Este es un cuidado ligado a la insuficiencia de pedagogía y al arte de aprender a gobernar y gobernarse dentro de los parámetros establecidos por la justicia y la verdad.

¿Y, qué es ese Sí Mismo del que hay que ocuparse, esa inquietud, esa "epimeleia"? A esta pregunta que surge en el texto repetidamente, el oráculo de Delfos responde: "Conócete a ti mismo." Este es el momento reflexivo del "gnothiheauton," que es el conocimiento del alma, dentro de un gobierno justo para sí mismo y para los demás. Por medio de la incisiva pregunta que utiliza al lenguaje como hilo conductor, Sócrates llega hasta este punto crucial: el cuidado del alma. Alcibíades debe cuidarla como sujeto, sujeto de acción, sujeto de conocimiento. Debe cuidar de su alma para gobernar y gobernarse, conocer y conocerse, con el cuerpo como vehículo del alma.

El conocimiento de Sí Mismo es un elemento constitutivo de la Inquietud de Sí. Esto es muy importante a lo largo de toda la civilización griega, helenística y romana, por sus implicaciones en la construcción de la subjetividad. (Foucault, 1982, p. 77.) Para conocerse hay que apartarse de las sensaciones engañosas, fijar el alma en una inmovilidad que no permita la influencia de acontecimientos externos. Hay que conocer a ese Sí Mismo del que hay que ocuparse, que es el cuerpo, que es el alma. Esto se logra 
a través de lo que nos devuelve la mirada del otro en el acto de transmitirnos su conocimiento. Este reflejo en la mirada del principio divino del saber dota al alma de sabiduría y habilidad para comportarse y gobernar como se debe. Es un reconocer lo divino en sí mismo. Es la acción cognoscitiva del alma como sujeto de sabiduría, de justicia y de verdad. Alcibíades dialoga y dialoga con su ignorante mirada siempre atenta en la de Sócrates quien lo interroga sin cesar, y responde para retornarse a sí mismo reformado, en un acto donde es capaz de recuperar su naturaleza verdadera.

Como pudimos apreciar, en esta época, es importante conocerse y a la vez ejercer el cuidado de sí para lograr gobernar la ciudad, es decir, ser efectivo en la política y en el arte de gobernar. Este es un cuidado de sí para adquirir conocimientos, reforzar la pedagogía y sobre todo conocerse para eventualmente lograr la optimización de sí mismo, siempre con la intermediación del otro. La presencia de ese otro marca la diferencia. El arte de pensar conduce a la verdad dentro de una subjetivación muy diferente a la que se construye en épocas posteriores bajo el ejercicio del poder y del saber como instrumentos de dominación. En este momento histórico el cuerpo físico es el vehículo del alma por cuidar, no es sujeto de dominación. Un vehículo que al empoderarse por medio del conocimiento se ha ido convirtiendo en el dueño de su vida y en el responsable de su circunstancia.

\section{En la época helénica}

Este es el Período del Alto Imperio, que se da en los siglos I y II d.c. con las filosofías cínica, epicúrea y estoica. Para Foucault (1982) es la Edad de Oro de la Inquietud de Sí, que pasa de la formación/saber en El Alcibíades a la corrección/ liberación en los estoicos. La Inquietud de Sí se transforma en un imperativo universal, dentro de un enfoque más vasto y crítico, donde el sujeto debe ocuparse de sí mismo como fin último de su existencia. El Yo es el objeto sobre el cual se desvela, ocupándose del gobierno de Sí y no del gobierno de los demás. Aprender a preocuparse y cuidar de sí mismo como objeto es una actividad adulta, continua y regulada, donde el Sí Mismo es el objeto de atención constante. Según el autor, en Platón la subjetividad se relaciona dialécticamente por medio del diálogo, mientras en este período hay temas relacionados a escuchar la verdad para encontrar la verdad dentro del Yo. Esta gran 
diferencia contribuye a la desaparición de la estructura dialéctica de la episteme antigua. (Foucault, 1990.)

La vejez y no la juventud, se convierte en el punto crucial como espacio de recompensa. Hay que darse prisa para llegar a esa plenitud que se alcanza en el ejercicio de la experiencia, donde el anciano es quien goza de sí mismo en la práctica del arte de vivir. En este tiempo, la Filosofía emerge como pensamiento de la verdad, de la búsqueda de sí, utilizando ciertas prácticas o tecnologías de Sí, la espiritualidad se vive más como vehículo de transformación que de salvación. Este es el momento de la ascesis filosófica donde se desarrolla y se ejerce una verdadera cultura de Sí como forma permanente de vida. La historia de la subjetividad y las relaciones entre el sujeto y la verdad se inscriben en el marco de una cultura donde el Yo que se ha organizado dentro de unas creencias, unas prácticas dadas y unos valores tradicionales.

Apropiarse de la verdad y por ende, de la subjetividad, se logra por medio del ejercicio constante de la memoria. También se obtiene por medio del saber callar y escuchar, del saber escribir y tomar nota de todo lo aprendido, del saber apartarse de la retórica y la adulación, y sobre todo del saber retornarse a sí mismo por medio del recuerdo. No es hacer del alma un lugar donde por derecho de origen reside la verdad, "es volver a ser lo que habríamos debido ser pero nunca fuimos, es dar al sujeto una verdad que no conocía, que no residía en él, es hacer de esa verdad aprendida progresivamente, un cuasi sujeto que reina entre nosotros" (Foucault, 1982, p.475.)

Desde esta perspectiva, el cuidado de sí mismo resulta ser una elección de modo de vida que va más allá del acto de ocuparse y conocerse a sí mismo en la juventud, Para lograrlo, son necesarias las prácticas sectarias, terapéuticas, culturales y religiosas, que, sin distingo de status, van dirigidas a la Práctica de Si por medio del dominio y conocimiento de sí mismo. El Yo es ahora el objeto absoluto de cuido y atención y las técnicas se practican dentro de una actividad de vigilancia donde el Yo se asegura el acceso al Sí Mismo, a su liberación y salvación, donde pocos logran la meta porque en el proceso se da una universalidad en el llamado y una escasez en la salvación.

En este contexto, se fundan las Escuelas Filosóficas Estoicas y Romanas como centros de reunión con alumnos regulares y, o pasantes donde algunos desean convertirse en filósofos, haciendo de la Filosofía un ejercicio profesionalizado.

Surge y se desarrolla, de esta manera, el examen de conciencia, donde la "libertas y la parrhesia," o la franqueza y la espontaneidad, son cruciales dentro de una práctica de Sí que para Foucault se manifiesta de forma muy diferente a la confesión 
dentro del cristianismo. Es entrenarse dentro de una técnica adulta que contiene cuatro expresiones o funciones: función crítica o deshacerse de malos hábitos, función de lucha o combate permanente, función curativa o dispensario del alma y función ilimitada del maestro como guía. "Es el ejercicio que involucra absorber una verdad dada por una enseñanza convertida en un principio interno, que es siempre permanente y siempre vigente en acción” (Foucault, 1982, p.474.) Para que la Práctica de Sí llegue a ese Yo al que apunta, éste debe constituirse como objeto y en este proceso siempre se necesita del otro en magisterio: magisterio del ejemplo, magisterio de los mayores, magisterio de la competencia, magisterio de saberes, magisterio del diálogo y de la turbación. Ya no es el maestro el que ilumina al otro con lo que debe conocer como sucedía entre Sócrates y Alcibíades, ahora tal y como está plasmado en las obras de Séneca y Marco Aurelio, existe un mediador en la formación del individuo como sujeto.

En este entorno, surge la salvación como algo fundamental y diferente a como se entendía el concepto dentro del cristianismo. Salvarse a sí mismo, se convierte en el objetivo principal de la vida y de la práctica filosófica. La salvación vista dentro de las Tecnologías de Sí, significa recuperar derechos, libertad e independencia. Salvarse es escapar de un riesgo que está siempre presente, es mantenerse en un estado continuo e inalterable de auto observación que asegura la felicidad y la serenidad. Es un estado que permite transitar de la muerte a la vida y del mal hacia el bien, donde el Yo, es el motor, el objeto, el instrumento y la finalidad de la salvación. "Quien se salva es aquel que se encuentra en un estado de alerta, en un estado de resistencia, en un estado de dominio y soberanía de sí que le permite rechazar todos los peligros, todos los ataques y todos los insultos." (Foucault, 1982, p. 183.)

Para Foucault la salvación es la liberación con respecto a aquello de lo que no somos amos, para llegar a aquello de lo que sí podemos serlo. Nos libera desviándonos de nosotros mismos, en un proceso donde sin perdernos de vista, logramos mirar la totalidad de la existencia. Es un saber útil que el Yo aprende apartándose en su silencio y soledad, para luego retornarse, logrando la soberanía que brinda el acceso a una verdad que luego es compartida. Para Séneca: "lo grande es tener el alma al borde de los labios y presta para partir; entonces somos libres no por derecho de ciudadanía, sino por derecho de naturaleza.” (Foucault, 1982, p. 422.)

Ese recorrer el gran ciclo del mundo, con el alma lista para partir, convierte a la vida misma en una continua prueba donde el ser humano, dentro de un contínuum se torna sujeto para sí mismo en libertad. Es el acto de retornarse, de subjetivarse, luego de 
contemplar la tierra desde ese punto en las alturas, donde la naturaleza le confirma al Sí Mismo que observado desde allí, es sólo es un pequeño punto en la vastedad del universo, donde al unísono se arraiga en su pertenencia. "En el estoicismo este recorrido es un pasaje de la sombra a la luz, donde se da una especie de modalización espiritual del sujeto, dentro de una "espiritualidad del saber" y una "práctica y ejercicio de la verdad" (Foucault, 1982, p. 305.) Esta práctica se logra en el silencio de la escucha y la distancia que eventualmente permite compartir las experiencias percibidas, dentro de una ética de la verdad sin cabida alguna para la retórica y la adulación.

Para Séneca, en primera instancia no se trata de descubrir la verdad en el sujeto, sino de recordar la verdad, de recobrar una verdad que ha sido olvidada. En segundo lugar, el sujeto no se olvida de sí mismo, ni de su naturaleza, su origen o su afinidad sobrenatural, sino de las reglas de conducta, lo que tenía que haber hecho. Tercero, el recuerdo de los errores cometidos durante el día, permite medir la diferencia entre lo que se ha hecho y lo que tendría que haberse hecho. Cuarto, el sujeto no es el punto de partida en el proceso de desciframiento, sino el punto donde las reglas de conducta se reagrupan en la memoria. El sujeto constituye la interacción entre los actos que han de ser regulados, y las reglas sobre lo que ha de hacerse. Esto es bastante distinto a la concepción platónica y a la concepción cristiana de la consciencia. (Foucault, 1990, p. 47.)

La figura del saber espiritual en Marco Aurelio correlaciona en cierto modo con la figura del saber en Seneca, pero en del Las Meditaciones, la práctica de este saber se realiza desde un sendero a la inversa. El movimiento espiritual del sujeto se da a partir del punto en que se encuentra en el mundo y en vez de proyectarse hacia lo alto, se hunde dentro del mundo, logrando de esta forma, examinar hasta el menor de los detalles. Este es el saber que se adquiere desde lo interno de la persona, donde el único instante de realidad, el único momento que importa en el proceso de subjetivación, es el presente. Es el instante de encuentro consigo mismo en que el Sí se topa con la impactante libertad de interiorizar lo que descubre sobre sí mismo en ese preciso e irrepetible momento. Es el acto de entrar al corazón de las cosas para adquirir la posibilidad de captarlas en su verdad y su valor real, en un proceso que se repite a lo largo de toda la vida. Este es el desplazamiento de la Conversión de Sí hacia el Sí Mismo que no es una renuncia de sí. Y es precisamente a partir de este proceso que profundiza en el conócete y cuídate a ti mismo, donde Foucault se hace una serie de preguntas conducentes a los albores del cristianismo, al poder pastoral y la modernidad.

¿No encontramos allí, en ese precepto helenístico y romano de la Conversión de Sí, el punto de origen, la raíz primordial de todas esas prácticas y conocimientos que se desarrollarán a continuación en el mundo cristiano y en el mundo moderno? ¿No encontraríamos allí la primera forma de lo que luego podría llamarse ciencias del 
espíritu, psicología, análisis de la conciencia, análisis de la psykhe, etc?. (Foucault, 1982, p. 305.)

En la construcción de la subjetividad durante este período que implica la Conversión de Sí, es imperativo enrumbarse hacia el interior de sí mismo. Es la "epistrophe," o retorno del alma a su fuente en un proceso de subjetivación constante. Un proceso donde hay que vivir retornándose, reencontrándose y reconvirtiéndose para apropiarse de la verdad sobre sí mismo y el mundo circundante.

\section{En los albores del Cristianismo}

Para Foucault, tardíamente con respecto al movimiento estoico, epicúreo y ascético, alrededor de los siglos III y IV se inicia el desarrollo del modelo cristiano o modelo ascético cristiano. En esta época temprana del cristianismo, el ascetismo siempre se refiere a una renuncia de sí mismo para acceder a otro nivel de realidad. Este deseo o impulso por llegar a la renuncia del propio Yo, distingue las prácticas cristianas de todas las prácticas o tecnologías anteriores. (Foucault, 1990, p. 76.) Siempre dentro de la búsqueda de la verdad, el individuo debe ahora purificarse para comprender La Palabra y acceder a la promesa de salvación. Este es el ejercicio continuo del "mea culpa" para disipar ilusiones, entregarse a la prueba, reconocer tentaciones, desbaratar seducciones y expiar culpas. Se da una Renuncia de Sí ante una institucionalidad religiosa que tiene el poder de revelar, rechazar o aprobar. Se reemplaza la verdad personal e íntima con la verdad institucional por medio de la penitencia dentro de una institucionalidad donde el individuo obedece.

Con el renunciamiento de sí se regula el orden de todos los sacrificios y de todas las pruebas, cobrando vigencia los procesos de culpabilidad. Esta renuncia abre espacio al momento cristiano de la Confesión, el momento del testimonio que requiere de una subjetivación de la verdad muy diferente a la que se daba en los siglos I y II donde al lado del maestro, la escucha, el silencio y el ejercicio ascético, eran la puerta de acceso a la verdad. Este es el momento de la Revelación donde la obligación de decir la verdad en la confesión estricta y operativa, se inscribe en la Pastoral como condición fundamental de la salvación eterna, donde el examen, la confesión, la obediencia y la penitencia son requisitos indispensables. "La penitencia es una forma de vida 
continuamente regida por la aceptación de tener que descubrirse a sí mismo, un deber de mostrar sus propias heridas." (Foucault, 1990, p.47.)

Este es el período donde la confesión de los pecados y el ejercicio de la vida sacramental desde la purga y la limpieza del alma, son fundamentales en la vía de acceso al perdón y la salvación. En este proceso de purificación y renunciación se hace necesario detectar a tiempo los movimientos equivocados que se originan en el alma, para luego colocarlos al servicio la confesión. (Foucault, 1982, p. 251.)

La idea de la vida como prueba ya no es sólo un pensamiento cumbre dentro de la meditación y otras prácticas estoicas y epicúreas, ahora se considera que la vida no es más que una prueba continua donde se habla de la salvación, la inmortalidad, la gracia y la confesión para lograr alcanzar la plenitud y la felicidad. Para el autor, el cristianismo expande y proyecta nuevas formas de poder en el mundo; un poder que indaga, dirige y exige por medio de los pastores para asegurar la salvación eterna:

El cristianismo no es tan solo una religión de salvación, es una religión confesional. Impone obligaciones muy estrictas de verdad, dogma y canon, más allá de lo que hacen las religiones paganas. Las obligaciones referidas a la verdad de creer tal o cual cosa, eran y son todavía muy numerosas. El deber de aceptar un conjunto de obligaciones, de considerar cierto número de libros como verdad permanente, de aceptar las decisiones autoritarias en materia de verdad; el no sólo creer ciertas cosas sino el demostrar que uno las cree y el aceptar institucionalmente la autoridad, son todas características del cristianismo. (Foucault, 1990, p. 47.)

Para Foucault ya no tenemos la libertad del Yo posándose en las alturas para retornar a sí mismo reformado, o bajando a las profundidades de su interior, para vivir la revelación que produce la subjetivación. Con el proceso de renunciación, el Yo se somete a un poder que se ejerce por medio del examen de consciencia y la culpabilidad, que sólo puede purgarse por medio de la mediación de un otro en confesión.

\section{En la Modernidad}

Si en el cristianismo no puede haber salvación sin renunciación, en la modernidad el retorno a Sí Mismo se vuelve de nuevo recurrente, instaurándose en los mecanismos de resistencia como parte de la subjetivación. (Foucault, 1982, p. 245.) En Foucault, la época moderna que inicia en el siglo XIX y se prolonga hasta nuestros días, la subjetividad está totalmente ligada al ejercicio del poder y del saber, convirtiendo la construcción del Yo en algo muy diferente a como se construía en tiempos anteriores. El saber, entendido como un espacio donde el sujeto se posiciona para hablar de los 
objetos acerca de los cuales trata su discurso, se ha convertido en un instrumento de poder institucionalizado dentro de las organizaciones sociales. Un instrumento que inicialmente penetra en la vida de las personas de manera panóptica y vigilante, para luego insertarse de forma pastoral y "rebañizadora." Es el poder capitalista, gubernamental, psiquiátrico, legal, escolar, familiar y religioso, donde la individuación y la discriminación se alcanzan solamente a través de los mecanismos de resistencia a la alienación que produce este poder y donde la estructura de la resistencia, ejercida desde los bordes, se convierte en antagonista.

En este período, las normas sociales dictan sobre el conocimiento y la identidad de sí, los pecados se ponen a la orden de la confesión y las personas bajo las leyes sociales que las juzgan, las vigilan y las castigan, condenando y encerrando sus cuerpos. Bajo estas condiciones, para lograr autenticidad y autonomía, el ser humano sólo puede ejercer el tipo de resistencia que engaña al vigía, pues se ha convertido en un ente atravesado por "una antropología que pone en duda su esencia, que habla de un hombre convertido en extraño para sí mismo, y por una economía que habla de mecanismos de control exteriores a la conciencia humana.” (Foucault, 1966, p. 221.) Esto convierte a la autonomía es un valor esencial en la construcción de la subjetividad, desde la resistencia. Cada quien debe gobernarse a sí mismo existiendo dentro de varios tipos de racionalidad política y estructuras de poder como el poder pastoral, o la razón del Estado. El pastor o jefe agrupa y categoriza a los sujetos-objetos que componen el rebaño para vigilarlos, controlarlos y eventualmente, conducirlos a una supuesta mejor calidad de vida.

El cogito moderno no conduce a una afirmación del ser, sino que se abre justamente a toda una serie de interrogaciones en las que se pregunta por el ser (p.316, ) el papel del pensamiento, su iniciativa propia, será acercarlo más al Sí Mismo; todo el pensamiento moderno está atravesado por la ley de pensar lo impensado, en reflexionar en la forma del Para Sí los contenidos En el Sí, de desenajenar al hombre reconciliándolo con su propia esencia." (p.318.) (Foucault, 1966.)

La modernidad se convierte en un enfrentamiento directo con la muerte, con la finitud personal y con el fin de la existencia, pero se vuelve a la vez, plataforma para el surgimiento de un hombre que logra pensar lo impensado. Para sobrevivir a su inevitable finitud y a los procesos de vida atravesados por el ejercicio del poder, los intentos de autonomía se plasman en el desarrollo de una indocilidad reflexiva, donde los seres tienen un cierto grado de libertad de pensamiento para lograr ver la racionalidad que hay detrás del poder, en su trasfondo. La resistencia no es ciega, es 
reflexiva porque se ejerce por medio de la razón. Si nos vamos a gobernar a nosotros mismos debemos saber cómo somos gobernados y qué posibilidades tenemos de construir una autonomía que nos permita ir hasta los límites de esa sujeción para luego, romperlos. Para Foucault en el poder del Estado, la sujeción y la dominación se entrecruzan con la explotación por medio del poder pastoral, que ejerce su poderío penetrando y hurgando en la vida del sujeto durante toda su existencia utilizando los binarios que categorizan a las personas y las colocan en puestos inamovibles que habría que romper para lograr la individualidad. Este poder necesita llegar a la verdad de una forma muy diferente a como se hacía en las épocas antiguas, necesita hurgar y conocer a su rebaño al interior y al exterior, para dirigir las conciencias que lo componen subyugándolas y clasificándolas. (Drayfus y Rabinow, 2001, p. 244 - 259.) En este sentido Foucault afirma:

Con el propósito de entender de qué se tratan las relaciones de poder, tal vez deberíamos investigar las formas de resistencia y los intentos hechos para disociar estas relaciones. Como punto de partida, tomemos una serie de oposiciones que se han desarrollado en los últimos años: la oposición del poder del hombre sobre la mujer, la de los padres sobre los niños, la de la psiquiatría sobre la enfermedad mental, la de la medicina sobre la población, la de la administración sobre la forma de vivir de la gente. (Foucault, 2001, p. 3.)

En el siglo XX, la intimidad y la individualidad se han sujetado y puesto a la orden del Estado, al servicio de instituciones de salud, educación, etc. El poder pastoral se ha expandido a estos niveles, teniendo información individual y utilizándola para sus fines. Nos hemos convertido en rebaños clasificados, presas de la institucionalidad económica y social, donde la resistencia debe ser cada vez más marcada ya que de alguna manera el poder también asigna un tipo de individualidad que ata al individuo a su propia lucha por su identidad, reafirmándola. Además de estar sujetos al poder pastoral, el cuerpo ha sido subyugado a los preceptos de la biopolítica. Este poder se sitúa sobre la vida de las personas e influye en todas sus relaciones instaurando la marginación y la exclusión. Es el poder de hacer morir y hacer vivir, de dejar vivir o dejar morir que se reproduce y sustenta por medio de la sujeción. Es la implantación del miedo y del atrapamiento; es el surgimiento del gran encierro que se manifiesta en las cárceles y en los manicomios. Es el poder jurídico, médico, pastoral y psiquiátrico que tiene en sus manos la decisión sobre la vida y la muerte, instaurando en las personas el miedo a su inminente finitud. "El cuerpo está inmerso en un campo político; las relaciones de poder operan sobre él como una presa inmediata, lo cercan, lo marcan, lo 
doman, lo someten a suplicio, lo fuerzan a unos trabajos, lo obligan a unas ceremonias, exigen de él unos signos.” (Foucault, 1975, p. 34.)

La igualización es la norma. Es el principio de regulación aplicado a los cuerpos, tal y como se aprecia en el caso de Herculine Barbin clasificado como un anormal, frente a lo que debería ser normal. Una persona hermafrodita sometida a exámenes médicos y múltiples confesiones que, al hurgar en su cuerpo, para cambiarlo, confunden su alma y al recalificarlo, zanjean su Yo, partiendo su identidad:

Me disgustaba verle afrontar por sí mismo mis secretos más queridos, y yo contestaba de forma poca medida a alguna de sus palabras, que me parecían una violación. En mí, me dijo entonces, no debéis ver solamente a un médico, sino también a un confesor. Si necesito ver, también necesito saberlo todo. (Foucault, 1980, p. 91.)

Foucault sostiene que dentro de los mecanismos de resistencia a esta objetivación del sujeto, podrían hallarse aquellos que incumben la afirmación y búsqueda de la verdad en relación con los procesos de construcción de la sexualidad: “A diferencia de lo que ocurre con otras prohibiciones, las prohibiciones sexuales están continuamente relacionadas con la obligación de decir la verdad sobre sí mismo" (Foucault, 1990, p.45.) Para él es importante romper los secretos y enfrentar todo tipo de prohibiciones, porque la sexualidad se ha utilizado como dispositivo de poder, en tanto que ha sido dominio del conocimiento del que tiene ese poder y ese saber.

Poder y saber se articulan en un discurso que debe ser concebido como una serie de segmentos discontinuos, cuya función táctica no es uniforme ni estable. Por lo tanto no debe pensarse en divididos, aceptable-excluido, dominante-dominado, sino como una multiplicidad de elementos discursivos que pueden actuar en estrategias diferentes (Foucault, 1999, p.122.)

Contrario a épocas anteriores, para él, los cuerpos modernos y por ende las identidades, están sometidos, normalizados, objetivizados, divididos, envueltos en continuas prohibiciones. Sobre la fragmentación que sufre el ser humano en la modernidad afirma:

En la segunda parte de mi trabajo he estudiado los modos de objetivación a los que yo llamaría "prácticas divisorias. El sujeto está dividido tanto en su interior como dividido de los otros. Este proceso lo objetiva. Los ejemplos son el loco y el cuerdo, el enfermo y el sano, los criminales y los buenos. (Foucault, 2001, p.1.)

Las personas diferentes son consideradas anormales y por tanto hay que controlarlas y subyugarlas. En este sentido, "la familia indefinida y confusa de los anormales, el temor de los cuales asediará el siglo XIX, se formó en correlación con todo un conjunto de instituciones de control, toda una serie de mecanismos de vigilancia 
y distribución.” (Foucault, 1974 p. 297.) Las personas desquiciadas que en la antigüedad andaban libres y metafóricamente se enviaban a recorrer las aguas del mundo en las "naves de los locos," en la modernidad son consideradas peligrosas y por eso hay que encerrarlas:

El papel represivo del manicomio es conocido: en él se encierra a la gente y se le somete a una terapia, química o psicológica, sobre la cual no tiene ninguna opción, o a una no-terapia que es la camisa de fuerza (...) ero la psiquiatría se prolonga en ramificaciones que van mucho más lejos, toda esa psiquiatría de la vida cotidiana que constituye una especie de tercer orden de la represión y de la policía, (...) la psiquiatrización de la vida cotidiana, si se la examinase de cerca, revelaría posiblemente lo invisible del poder.” (Foucault, 1971, p. 40.)

En el intento de construir y mantener la identidad, se subsiste en una continua lucha desde una resistencia en contra de una peligrosidad instituida desde afuera, que amenaza con la fragmentación y la despersonalización total. Dentro de la estructura moderna, el cuerpo se ha convertido en un objeto productivo y útil, atravesado por el poder estatal, pastoral, médico, psiquiátrico y legal.

La conclusión podría ser que el problema político, ético, social y filosófico de nuestros días no es tratar de liberar al individuo del Estado y de las instituciones del Estado sino liberarnos de ambas, del Estado y del tipo de individualización que está ligada a éste. Debemos promover nuevas formas de subjetividad a través del rechazo de este tipo de individualidad que nos ha sido impuesta durante siglos. (Foucault, 2001, p. 7.)

Se establece una lucha que gira en torno a la cuestión de quienes somos, en contra de un poder que ignora que somos personas individuales, objetivizándonos. Se lucha contra la forma de dominación vista como una estructura general de poder que penetra en todas las fibras de la sociedad; se lucha contra todas las formas de explotación laboral y social y contra todas las formas de sumisión y sujeción personal. El poder pastoral y vigilante es el que dicta el grado de autonomía personal, convirtiendo al proceso de subjetividad en algo que depende de una lucha en contra de de una visión externa a sí mismo. La libertad y la verdad se implantan y dictan desde afuera atrapando la individualidad.

\section{Conclusiones}

$\mathrm{Al}$ incursionar en el tema de la construcción de la subjetividad en algunos textos y discursos de la extensa obra de Michel Foucault, hemos visto como la construcción del sujeto, se realiza en formas muy distintas en cada una de las épocas recorridas. En el momento greco/romano el sujeto joven emprende un viaje hacia Sí Mismo dentro del proceso del cuido de sí y la búsqueda de la verdad con la mediación de un maestro. En 
el período del Alto Imperio se pasa de la formación/saber a la corrección/liberación, donde la Inquietud de $\mathrm{Si}$, dentro de unas técnicas específicas se convierte en un imperativo universal, dentro del cual el sujeto adulto debe ocuparse de sí mismo como fin último, para volver a ser lo que habría debido ser, pero nunca fue. En los albores del cristianismo hay una renuncia de sí mismo, una mea culpa y una obediencia, donde se instaura un poder pastoral organizado a través de mecanismos confesionales para asegurar la salvación del alma.

Finalmente, en la Modernidad la construcción del sujeto y su cuerpo, es sometida a un poder y un saber que atrapa, vigila y castiga, donde la única posibilidad de construirse a sí mismo es por medio de la resistencia a los binarios desiguales aplicados a los cuerpos. El cuerpo humano, que en la antigüedad se había convertido en receptáculo de conocimiento, vehículo del alma y sujeto de cuidado e introspección minuciosa, en la modernidad se ha transformado en el cuerpo del rebaño inmerso en la desigualdad, sujeto a un poder y un saber al que hay que resistir. Los procesos de encerramiento, de reificación y enajenación propios de nuestra era, demandan resistencias y soluciones basadas en técnicas y saberes de sí, muy específicas para estos tiempos de lucha, donde se pretende la total objetivación del sujeto. Para el autor, la construcción de la subjetividad hoy en día se logra solamente a través del ejercicio de lo que él llama la indocilidad reflexiva en contra de lo que nos ha sido impuesto.

\section{Referencias bibliográficas}

Abreo, A.M. (2011). El gran método de Foucault: Una arqueologíagenealógica y una genealogía-arqueológica. Revista Papeles, 3(6). Recuperado de http//csifesvr/uan.edu.co/index.php/pepeles/article/download/191/168.

Dreyfus, H. y Rabinow, P. (2001). Más allá del estructuralismo y la hermenéutica. Buenos Aires, Argentina: Nueva Visión.

Foucault, M. (1966). Las palabras y las cosas. Argentina: Siglo XXI.

Foucault, M. (1971). Nietzsche, la genealogía, la historia, en Hommage a Jean Hyppolite. Paris, France: Ed. PUF.

Foucault, M. (1974). Los anormales. México: Fondo de cultura económica.

Foucault, M. (1975). Vigilar y castigar. Argentina: Siglo XXI.

Foucault, M. (1980). Herculine Barbin. Argentina: Talasa Ediciones. 
Foucault, M. (1982). La hermenéutica del sujeto. México: Fondo de cultura Económica

Foucault, M. (1990). Tecnologías del yo. Barcelona, España: Editorial Paidós.

Foucault, M (1999). Historia de la sexualidad. Argentina: Siglo XXI.

Foucault, M (2001). El sujeto y el poder. Argentina: Epílogo a la Segunda Edición de Más allá del estructuralismo y la hermenéutica. Buenos Aires: Nueva Visión.

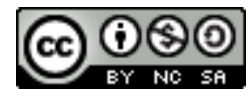

Esta obra está bajo una licencia de Creative Commons Reconocimiento-NoComercialCompartirIgual 4.0 Internacional. 